\title{
The Contribution to Low-Carbon Transportation and Energy Saving of Equilibrium Configuration on Traffic Resources
}

\author{
Shouhong Ren ${ }^{1, a}$, Zhifei Xie ${ }^{2, b}$ and Shuo Tian ${ }^{3, c}$ \\ ${ }^{1}$ Department of College of Civil Engineering, Inner Mongolia University of Technology, \\ Aimin Street 49 , Hohhot, China \\ ${ }^{2}$ Department of College of Civil Engineering, Inner Mongolia University of Technology, \\ Aimin Street 49 , Hohhot, China \\ ${ }^{3}$ Department of College of Civil Engineering, Inner Mongolia University of Technology, \\ Aimin Street 49 , Hohhot, China \\ am13604717375_1@163.com, 'b56284708@qq.com, 'c1968906844@qq.com
}

\begin{abstract}
Keywords: Low-Carbon Transportation, Energy Saving, Emission Reduction, Environmental Protection, Traffic Resources

Abstract. Considering the country attaches great importance to energy conservation and emission reduction, Low-carbon transportation and the commuting of Hohhot's serious transportation inefficiency causes the destruction of the atmosphere and the useless consumption of energy, time and other resources, as well as having adverse effect to the local resident's life, we have executed the massive questionnaires and interviews to the residents of Hohhot, and have consulted the relevant departments. Through collection of the first material and analysis of data, we have a more comprehensive understanding to the traffic symptom of Hohhot. By means of investigation, induction and analysis, we have discovered if we want to improve the present traffic condition of Hohhot fleetly, we must allocate evenly the traffic resource, especially the rapid development of the public transport.
\end{abstract}

\section{Introduction}

In the past few years, along with the growth of national economy, the process of urbanization speeds up significantly. The pedestrian volume, physical distribution and information stream radiate to the big city and the surroundings rapidly. Urban population concentrate constantly, the scale of cities expands continually, and the fast development has led the growth of the demand of municipal transportation. The quantity of motor vehicle increases sharply in many big cities of our country, and the growth rate surpasses $10 \%$ yearly, the condition of traffic load aggravates day by day in our country. The question of traffic congestion just likes the malignant tumor of the urban development. It caused the journey inefficiency, the increase of fuel expense, the loss of time and the destruction of urban environment and so on

As the capital of the The Inner Mongolia autonomous region and the transport hub of the northwest, the local economy of Hohhot, foreign investment and exchange activities of cultural are booming. Just like many other cities in China, as a symbol of the improvement of people's living standards, the quantity of motor vehicle has maintained double-digit high growth in recent years. The people who live in Hohhot are feeling obviously that the traffic congestion is serious increasingly. The interval time of bus is so long, people who appear at the bus station are too many to get on. People could not take a taxi, carpooling has become the norm. The illegal taxi is scampering in anywhere. The serried private cars spurt jet tail gas continually, the haze in the air stimulate the mouth and nose of us. Chunks of time is wasted, a lot of energy and other resources are consumed stealthily.

The question of traffic congestion is the associated product of social and economic development, and it is a problem that the nations of the world can have in the course of urbanization. The traffic jam can cause various influences to the society, including the waste of time, the increase of energy consumption, the pollution of environment (air pollution, noise pollution and the ozone depletion that 
comes from tropical island effect) and the occurrence of road accident as well as the worsening of people's mood and so on.

Traffic congestion that Hohhot manifests - said accurately it is the transportation inefficiency seriously. It affects the work and life of resident badly, and restricts the sustained, rapid and healthy development of economy of Hohhot. Traffic jam becomes a secret worry of capital all levels of department and resident. Therefore, the improvement of municipal traffic can reduce the environmental pollution and use resources effectively. It means a great deal to Hohhot.

\section{Research and analysis}

The study on reasons of inefficient traffic had been completed. The main features of traffic jams are as follows:

Time characteristics-It is serious when people go to and after work.

Geographical characteristics-The congestion happens in transportation center such as Railway station and long-distance bus station, hospital, school and market.

Outstanding characteristics-The renovation of the city's main roads and slip roads each year in Hohhot caused unnecessary congestion.

The main performance and reason of the inefficient transportation are as follows: the limited bus resource, unscientific public transportation network planning and unscientific public transportation network planning puts loading pressure on some sections of roads and brings great inconvenience to passengers. Many new communities or a remote section of the bus traffic do not pass bus, bringing a lot of inconvenience to people. Because of the low economic benefits of remote lines, some buses do not depart on time, which greatly increases the waiting time and pressure.

The unsatisfied market requirements are as follows:

At present, some public buses on use which are broken badly, make safety and riding comfort lower. The vehicle emission pollutes the air.

The unreasonable settings of bus stop limited the city's development.

In recent years, the bus stop has been improving, but still it doesn't have a unified standard, for example the different appearance of station boards, the places of boards changed frequently. Some boards which are set on the sidewalk cause new traffic jams. Some boards make small space for passengers seriously affecting bus efficiency.

The inconsistent service of public transportation is the one of the other cause.

Some citizens go out at night cannot catch up the last buses because of early off-running time. Public buses do not have the consistent principle on commuter time.

The Fewer bus lane is the another reason. Implementation of bus priority requires that bus lanes should be established first and not only wide roads but also specialized needs in the traffic lights junction. This junction at least needs 6 to 8 lanes. But two bus lanes in Xin Hua Street and Xi Hua Dong Street Obviously cannot meet the rigid requirements.

The imperfection of public transport facilities is the last reason-the insufficient public transportation financial compensation. At present, the proportion of governmental public transportation capital is $15 \%-16 \%$ of GDP, which makes a big gap between current situation and governmental goal. The insufficient public transportation financial compensation, the bad pay and low well-being of driver, the small quantity of parking lots, the low resource use efficiency; the insufficient paying attention to urban public transportation management, many traffic signal are not clear make public transportation go weaker. Furthermore, the unreasonable settings of transit line, the long detour, the small quantity of bus lance, the low ability of evacuating, the poor services make slow development of public transportation.

The bus transport capacity limited the city's development also. At present, excepting for hinge bus of No.3 bus and double-deck bus of No.102, most buses in Hohhot have limited transport capacity, which cannot bear the heavy burden of peak-hour in most cases. This situation leads low operation efficiency. 
The unreasonable setting of traffic signal is a trouble. after a period of investigating, we find that the traffic jam happens in left-handed lane, just the opposite, the straight going lane has convenient communications. This shows the unreasonable setting of traffic signal in some sections of road. For example, the quantity of left-handed lane is small, the waiting time of left signal light is too short.

The parking problems are also tricky. At present, the parking hard in Hohhot is a certain fact, the increasing speed of urbanization, rapid growth of vehicle population, but because of planning and construction of parking facilities and parking management is lagging behind, resulting in a lot of parking problems. By temporal and spatial distribution analysis, we found the rigid motor vehicle growth, delayed construction of parking facilities planning, transportation imperfect, irrational function, constraints such as lack of mechanisms that affect the look of the city parking is difficult and space distribution of the main factors.

The illegal taxis question is serious. with the road transport market growing, the phenomenon of illegal operation which is driven by interests showed the trend of increase in the road transport market. Otherwise the black cars cannot guarantee passengers safety. Without trading certificates, it is hard for passengers to complain. Because of most black cars coming from the second-hand cars, it is easier to have accidents in bad weather.

The poor road sense and traffic legal awareness of most private car drivers are poor.at present, insufficient safety education leads that most drivers persist in their old ways without paying attention to traffic legal institution. This situation makes private car owners disregard the traffic laws, traffic police management and even life safety, which disturbs the public orders. furthermore, with the rising number of private car owners, the government management department has poor ability of dealing with traffic condition, which leads to lots of traffic accidents.

\section{Solution for traffic inefficiency}

The solution of imperfect traffic communal facilities. Improving traffic laws in Hohhot. According to the urban management planning, Hohhot should make a local regulation and complete the traffic laws, enhance City monitors are in urgent need of construction. The misfeasor must be punished to strengthen law enforcement, fighting against black cars to reduce safety risks.

Increasing input of public transportation financial compensation.

Investing in public transportation, improving the quality of buses, optimizing public traffic network and increasing service time will make citizens give up their private cars, which alleviates traffic jam, reduce traffic accidents, energy-saving and exhaust gas emission.

The fast construction of bus lanes is under way. To minimize interference between buses and other vehicles and to improve the public transit services, the design of exclusive bus lane increasingly becomes diversified and elaborative. Priority of public transportation is one of the most effective methods to address traffic congestion, which is lead from traffic supplies cannot meet the demand under the urban shortage of transport resources. Setting up bus lane is one of the bus priority measures. The bus lane could be set up to improve bus operating environment, improve bus speed and reduce delays. These may ensure the operation of the bus punctuality rate and improve public transport services to lead to the most optimal allocation of traffic resources. The bus lanes are set up to promote the development of public transportation. It is also an effective way to ease the pressure on urban traffic. The exclusive bus lane should be set in main road in Hohhot.

Increasing the number of public traffic transportation is one of improvement methods.the squeezing and long-playing waiting make people reluctant to take a bus. Increasing the number of public bus can shorten waiting hours, which meets citizens' requirements and change the trip mode.

It is necessary to control strictly the number of private cars. Investing to control the number of private cars. Increasing cost is a strict way to control the number of private cars. If the cost of buying and maintaining cars are rising, the number of private cars will be controlled.

Strict control in offering driving licenses is necessary. the strict control in offering driving licenses can improve people's ability of driving. Driving schools should be strict with everyone in 
examination. At the same time, struggling against corruption in giving up licenses and making more difficult in passing the driving exam can guarantee the quality of driving licenses.

Increasing the working cost of private cars is perhaps unreasonable. Increasing the working cost of private cars includes the traffic restriction based on the last digit of license plate number, the license plate lottery, charging congestion fee and putting up the price of gasoline.

Encouraging use of Public transport facilities is a good idea. The citizens who use public transport facilities can be given economic benefits. The government should establish a normative evaluation system of cost and a Policy-related losses evaluation system to make the annual audit and evaluation for public transport enterprise costs and increase the social welfare of public transport enterprises.

\section{Conclusion}

Traffic congestion and inefficiency is currently a major disease in Hohhot. Improvement of urban traffic environment has become the work which government and the public are most concerned about. Balanced allocation of transport resources is the inevitable trend of development of traffic. It is directly related to the construction of the city, even China's social transformation and long-term development. The quality of traffic has a direct impact on the status and quality of local residents 'life.

The imperfect public transportation facilities makes residents not willing to take the bus as the primary means of transportation, but to choose private cars, which causes the traffic jam phenomenon and a great deal of waste in time and resources. As a result, bus priority which can reduce the number of private cars, make black cars vanish and realize natural distribution of traffic resources is an important way to improve people's quality of life and achieve "energy-saving and low-carbon".

\section{References}

[1] Huiyuan Jiang, Yongshen Huang:Study on Early Warning of Traffic Resources and Environment Carrying Capacity(Wuhan University of Technology, 2015), in Chinese.

[2] Zhiyong Zhou, Jun Hen, Wei Wang: Urban Mechanized Vehicle Traffic Resource Condition Fuzzy Synthetic Judgment Research. Computer and Communications ,2004, in Chinese.

[3] Guanjun Cao:Elementary Discussion on Development Strategy of City Bus Priority . Urban Roads Bridges \& Flood Control,2015.

[4] Yong Wu:The Policy Orientation on China's Urban Public Transport in the Process of Urbanization Development $\{$ M \}.Beijing: China social sciences press, 2001, in Chinese.

[5] Huiyuan Jiang:Bus Priority-break through the Bottleneck of Urban Traffic $\{\mathrm{J}\}$.Urban public transport,2008, in Chinese.

[6] Xiaobo Sun:The Urban Traffic Management and Reform Research in China $\{\mathrm{D}\}$.Wuhan: WuHan University of Technology,2003, in Chinese.

[7] Jie Wen,Dan Li,Yan Zhang:Insist on Bus Priority, to Push to Improve Urban Traffic Conditions in China $\{\mathrm{J}\}$.Urban public transport,2010, in Chinese. 